\title{
各種窒化ケイ素球の摩耗特性
}

\author{
岩佐美喜男・木下 実 \\ (大阪工業技術試験所, 563 池田市緑丘 1-8-31)
}

\section{Wear Behavior of Silicon Nitride Ball}

\author{
Mikio IWASA and Makoto KINOSHITA
}

(Government Industrial Research Institute, Osaka, 8-31, Midorigaoka 1-chome, Ikeda-shi

563)

The ball-on-disk method was applied to measure the wear behavior of $\mathrm{Si}_{3} \mathrm{~N}_{4}$ balls sliding on $\mathrm{SiC}$ disk at the load of $10 \mathrm{kgf}$ and velocity of $20 \mathrm{~cm} / \mathrm{s}$. Four kinds of $\mathrm{Si}_{3} \mathrm{~N}_{4}$ balls from different sources were named $A, B, C, D$, in increasing order of their hardness or fracture toughness. The large grain structure and large porosity of $S_{3} N_{4}(A)$ will explain its low hardness and low fracture toughness. The fine fibrous structure without porosity of $\mathrm{Si}_{3} N_{4}(D)$ may be the reason of its high hardness and high fracture toughness. The wear volume calculated from the wear scar on a $\mathrm{Si}_{3} N_{4}$ ball sliding on the SiC disk was proportional to the weight loss and to the sliding distance. The wear of $\mathrm{Si}_{3} \mathrm{~N}_{4}$ ball decreased with increasing hardness or fracture toughness, but on the contrary, the wear of $\mathrm{SiC}$ disk increased sharply. The $\mathrm{Si}_{3} N_{4}(C)$ ball, which has crystallized grain boundary phases, showed very low wear of ball but high wear of SiC disk.

[Received August 18, 1988; Accepted October 21, 1988]

Key-words : Ball-on-disk method, Silicon nitride ball, Silicon carbide disk, Vickers hardness, Fracture toughness, Wear scar, Specific wear rate

\section{1. 緒 言}

高温, 腐食性などの厳しい雾囲気に耐え, 無潤滑で使 用できるなど，窒化ケイ素製のボールベアリングはその 優れた特性が注目されている(1),2). 各所で焼結加工法や 性能評価に関する研究開発が進められ, 一部では既に商 品化, 市販されている31,4).

そのようなベアリング素材の基礎データである摩擦・ 摩耗特性を検討するため, 入手可能な 4 種の窒化ケイ素 球について, ボールオンディスク法による摺動試験を実 施した ${ }^{5), 6)}$. ボールオンディスク法とは, 回転するディ クス試料に球試料を押し付ける試験法である. 他の方法 に比べて剛性の高い試験ができ，また試料の重量減少の みではなく生ずる摩耗痕の形状からも摩耗量を求めるこ とができるなど，ボールベアリングに期待される厳しい 摺動条件に適した試験法であると言える，なお，ボール オンディクス法による鋼球とセラミックス間の摺動試験 については既に報告している7).

\section{2. 実 験}

ボールオンディクス法の概要を図 1 に示した。窒化ケ イ素試料 $\left(\mathrm{Si}_{3} \mathrm{~N}_{4}\right)$ はすべて直径 $10 \mathrm{~mm}$ で, 真球度 0.1 $\mu \mathrm{m}$, 表面粗さ $R_{\mathrm{a}}=0.02 \mu \mathrm{m}$ 以下に仕上げられた真球で あり,また相手ディスクにはホットプレス炭化ケイ素 ( $\mathrm{SiC}$, 密度 $3.17 \mathrm{~g} / \mathrm{cm}^{3}$, ビッカース硬度 $2600 \mathrm{kgf} / \mathrm{mm}^{2}$ ) を用いた. 球試料は圧縮空気駆動のベロフラムタイプシ リンダーにより，回転するディスク試料に押し付けられ
る. 押付荷重は $10 \mathrm{kgf}$, ディスク回転数は $150 \mathrm{rpm}$ とし, 摺動円の直径が $25 \mathrm{~mm}$ なので摺動速度は約 $20 \mathrm{~cm} / \mathrm{s}$ 亡 なる．摩擦トルクをベンディングロードセルで測定し， 摩擦係数 $(\mu)$ を求めた. $\mathrm{Si}_{3} \mathrm{~N}_{4}$ 球の摩擦量 $W_{\mathrm{b}}$ は生ず る摩耗痕の直径 $d$ を計測顕微鏡で測り, 球の半径を $r$, 摩耗深さを $h$ として, 次式から求めた.

$$
W_{\mathrm{b}}=\pi h^{2}\left(r-\frac{h}{3}\right), h=\frac{(d / 2)^{2}}{r+\sqrt{r^{2}-(d / 2)^{2}}}
$$

一方，ディスクの摩耗量 $W_{\mathrm{d}}$ は摺動円の断面形状を表面 粗さ計で測り, 積分して体積とした.いずれも単位荷重, 単位摺動距離当たりの摩耗体積, 比摩耗量 $W_{\mathrm{s}}$ に換算し て相互比較を行った. 各 $\mathrm{Si}_{3} \mathrm{~N}_{4}$ 試料の破断面や摺動面な ごの様子は走查型電子顕微鏡 (SEM) で観察した.

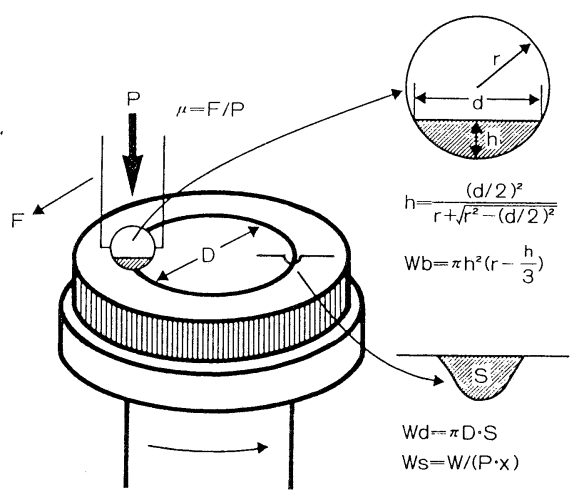

Fig. 1. Schematic illustration of ball-on-disk method. 


\section{3. 結果と考察}

実験に使用した 4 種の $\mathrm{Si}_{3} \mathrm{~N}_{4}$ 球， $\mathrm{A}, \mathrm{B}, \mathrm{C}, \mathrm{D}$ を切断, 鏡面研磨し, 荷重 $10 \mathrm{kgf}$ でのビッカースインデンテー ション法により，硬度（ $\left.H_{\mathrm{v}}\right)$ および Niihara の式による 破壊䩲性 $\left(K_{\mathrm{IC}}\right)$ を測定した ${ }^{8), 9)}$. それらの $H_{\mathrm{V}}$ と $K_{\mathrm{IC}}$ の 関係を図 2 に示したが， $H_{\mathrm{v}} ， K_{\mathrm{Ic}}$ とも $\mathrm{A}$ が最小，D が 最大，その中間に $\mathrm{B} ， \mathrm{C}$ がある. 図 3 に破断面，図 4 にビッカース圧痕の SEM 写真を示したＡ A は等方的で

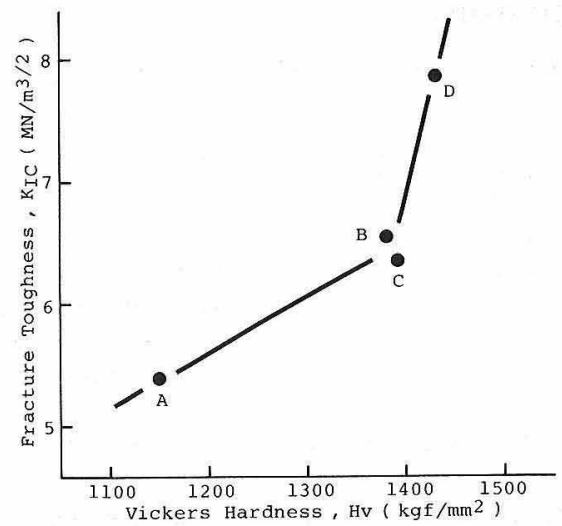

Fig. 2. Relation between Vickers hardness and fracture toughness of the $\mathrm{Si}_{3} \mathrm{~N}_{4}$ balls used.

A

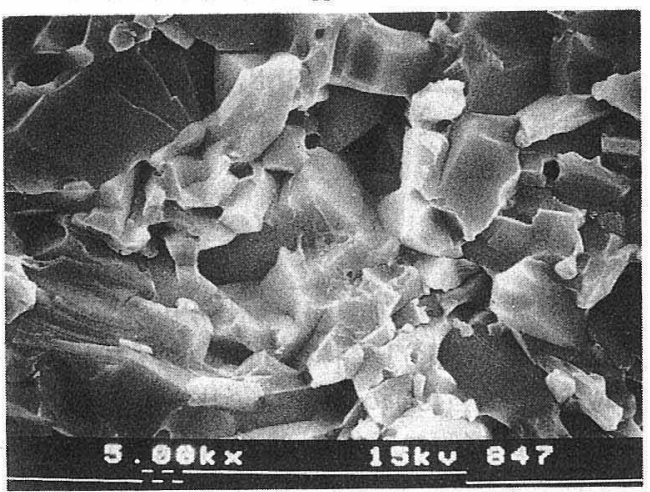

B

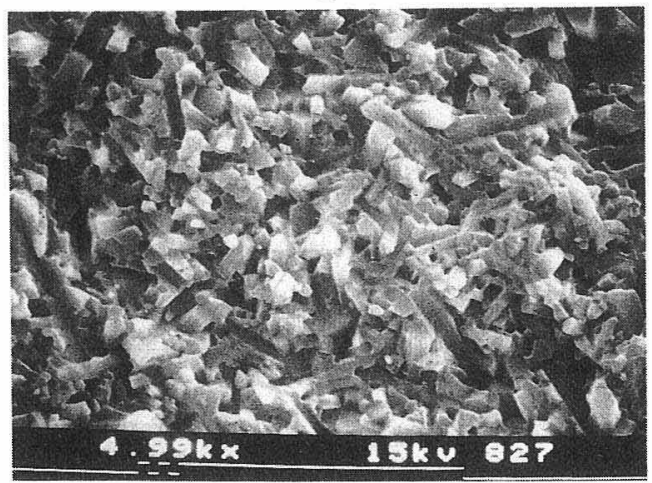

数 $\mu \mathrm{m}$ と大きく成長した粒子からなっていて，しかも気 孔がかなり多い.それが低い $H_{\mathrm{v}}, K_{\mathrm{IC}}$ の原因と思われる. それに比べて，D は高靶性な $\mathrm{Si}_{3} \mathrm{~N}_{4}$ に特有な非常に微細 な針状組織を持ち，気孔もほとんどない，B，Cも気孔 は少ないが，D よりも若干粒子径が大きく， $H_{\mathrm{v}}, K_{\mathrm{Ic}}$ が いくらか低い原因であろう. 図 5 にX 線回折の結果を 示した. $\mathrm{A}, \mathrm{B}, \mathrm{D}$ では $\beta-\mathrm{Si}_{3} \mathrm{~N}_{4}$ のみの回折ピークが検 出され，Cにはそれ以外に結晶粒界相である Melilite 相が認められる.

$\mathrm{Si}_{3} \mathrm{~N}_{4}$ 球， $\mathrm{D}$ につて摺動距離を約 $1 \mathrm{~km}$ から $80 \mathrm{~m}$ ま で 6 段階にかえて測定した摩耗量 $W_{\mathrm{b}}$ と，そのときの球 の重量減少との関係を図 6 に示した．すべての測定点が $\mathrm{D}$ の密度 $3.23 \mathrm{mg} / \mathrm{mm}^{3}$ に相当する直線上に分布してい ることから，鋼球と同様， $\mathrm{Si}_{3} \mathrm{~N}_{4}$ についても摩耗量の測 定に（1）式が適用できることが分かった7). 次に，摺 動距離による摩耗量の変化が図7であるが，摺動距離に ほぼ比例して摩耗量が増加している，そこで，最小二乗 法による近似直線を求め，その傾きから比摩耗量が $W_{s}$ $=2.8 \times 10^{-7} \mathrm{~mm}^{2} / \mathrm{kgf}$ 亡計算される.

同様な結果が他の $\mathrm{Si}_{3} \mathrm{~N}_{4}$ 球についても得られ，各 $\mathrm{Si}_{3} \mathrm{~N}_{4}$ 球の比摩耗量を $H_{\mathrm{v}}$ の関数として図 8 に示した. 同図にある $\mathrm{SiC}$ ディスクの比摩耗量は図 9 に示すよう

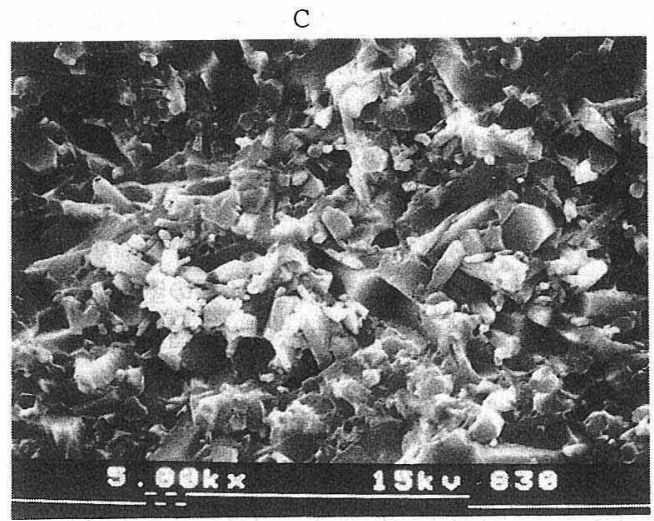

D

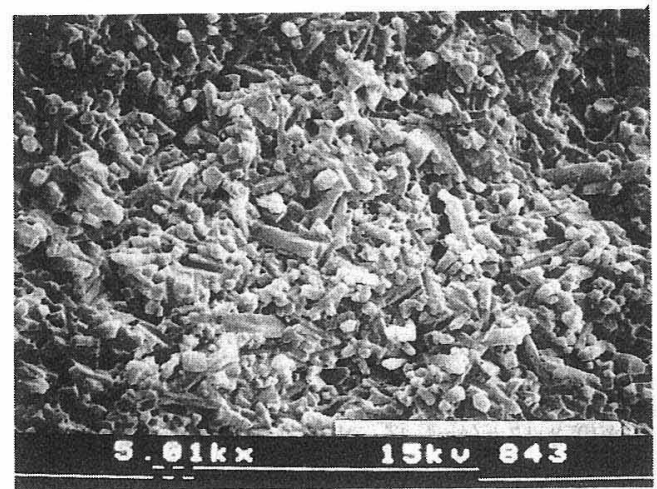

Fig. 3. Fractured surfaces of $\mathrm{Si}_{3} \mathrm{~N}_{4}$ balls. The lines are $10 \mu \mathrm{m}$ in length. 

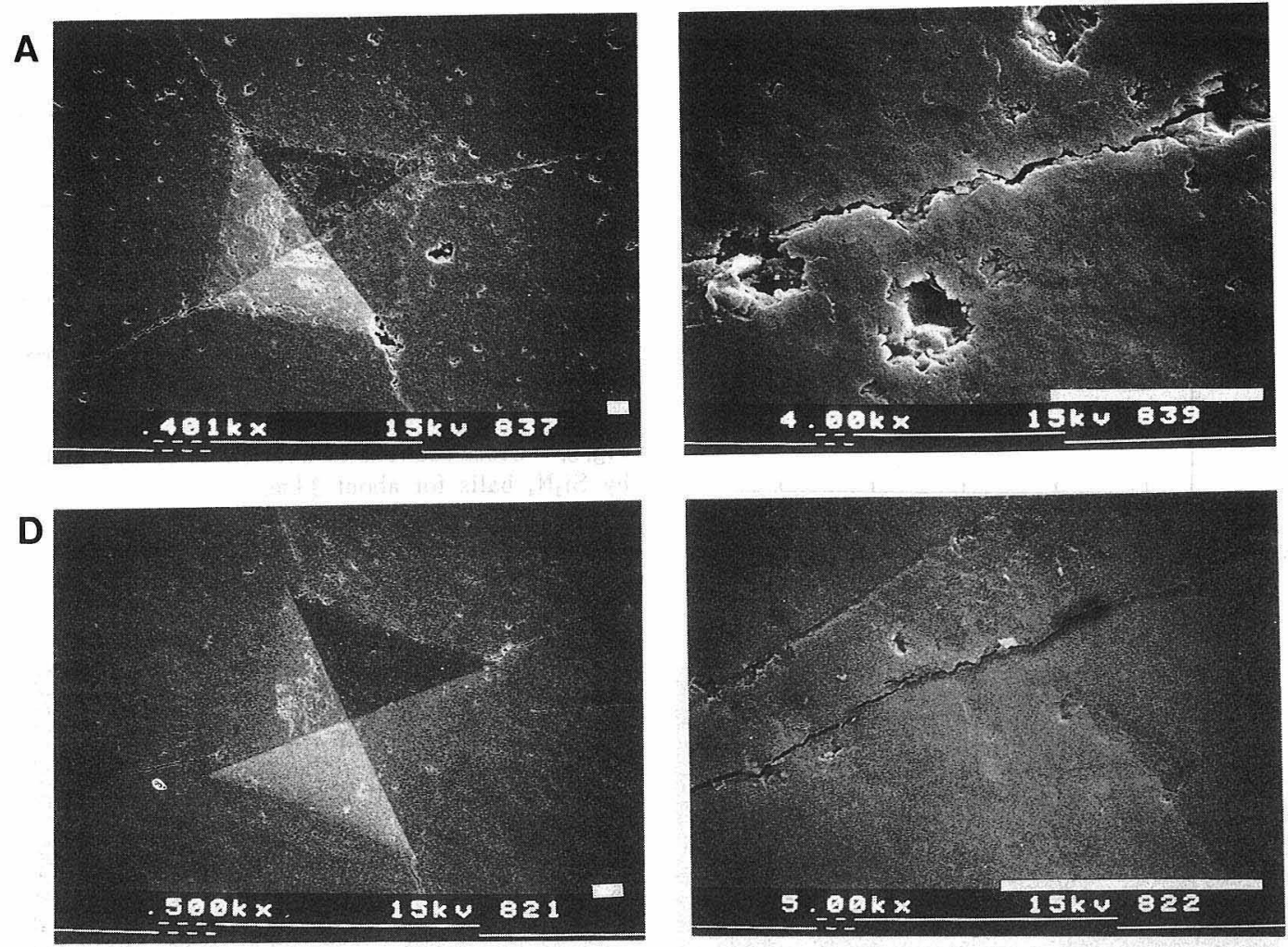

Fig. 4. Vickers indentation on polished surfaces of $\mathrm{Si}_{3} \mathrm{~N}_{4}$ balls. The lines are $10 \mu \mathrm{m}$.

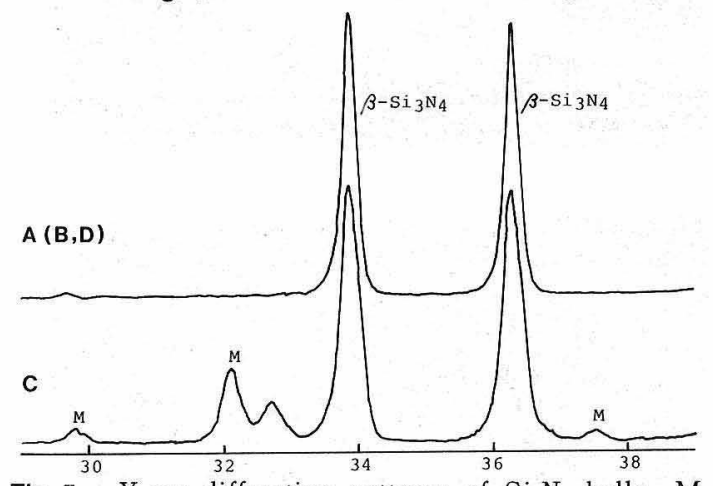

Fig. 5. X-ray diffraction patterns of $\mathrm{Si}_{3} \mathrm{~N}_{4}$ balls. $\mathrm{M}$ indicates Melilite phase.

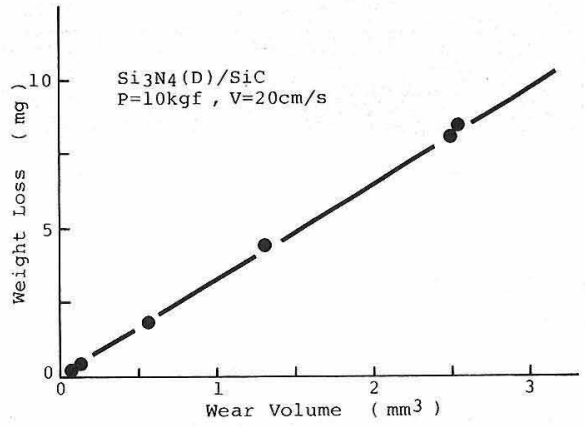

Fig. 6. Relation between wear volume from the wear scar and weight loss of $\mathrm{Si}_{3} \mathrm{~N}_{4}$ (D) ball sliding on $\mathrm{SiC}$ disk.

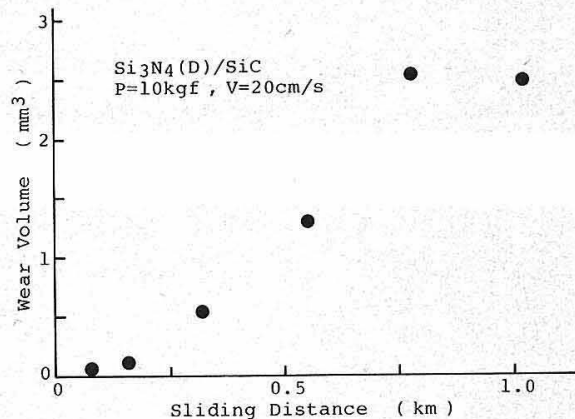

Fig. 7. Wear volume of $\mathrm{Si}_{3} \mathrm{~N}_{4}$ (D) ball sliding on $\mathrm{SiC}$ at load $10 \mathrm{kgf}$ and velocity $20 \mathrm{~cm} / \mathrm{s}$, as functions of sliding distance.

な搨動円の断面形状から求めたものである.なお, 摩擦 係数はいずれも $\mu=0.75$ 前後であり, $\mathrm{Si}_{3} \mathrm{~N}_{4}$ 球による差 異は認められなかった. $\mathrm{Si}_{3} \mathrm{~N}_{4}$ 球の摩耗は $H_{\mathrm{v}}$ あるいは $K_{\mathrm{IC}}$ が高くなると減少し, 逆に $\mathrm{SiC}$ ディスクの摩耗は急 速に増大している. 各 $\mathrm{Si}_{3} \mathrm{~N}_{4}$ 球上の摩耗痕の様子が図 10 であるが，いずれも表面凹凸が激しく，完全に脆性 破壊的な様相を呈している.このようなシビア摩耗では, 試料の硬さや鞀性が高いほどそれ自身は摩耗せず相手を より摩耗させる，とある程度までは単純な説明ができる のかもしれない, しかし, 結晶粒界相を含むCの摩耗 は非常に低く, 逆に相手ディスクの摩耗は高くなってい 


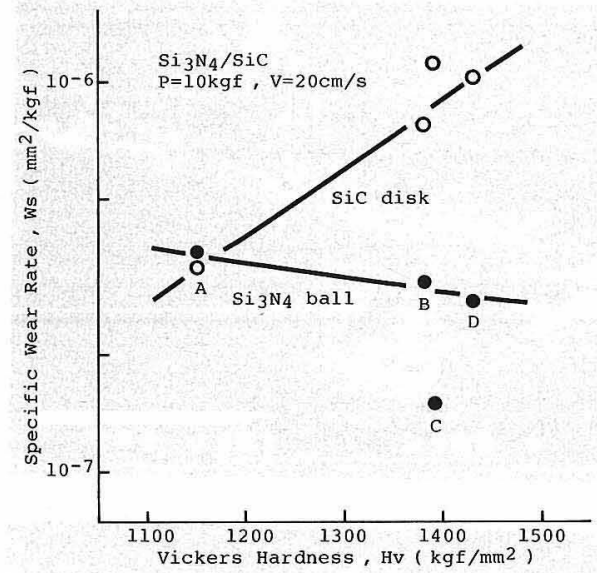

Fig. 8. Specific wear rates of $\mathrm{Si}_{3} \mathrm{~N}_{4}$ ball and $\mathrm{SiC}$ disk, in relation to its Vickers hardness.

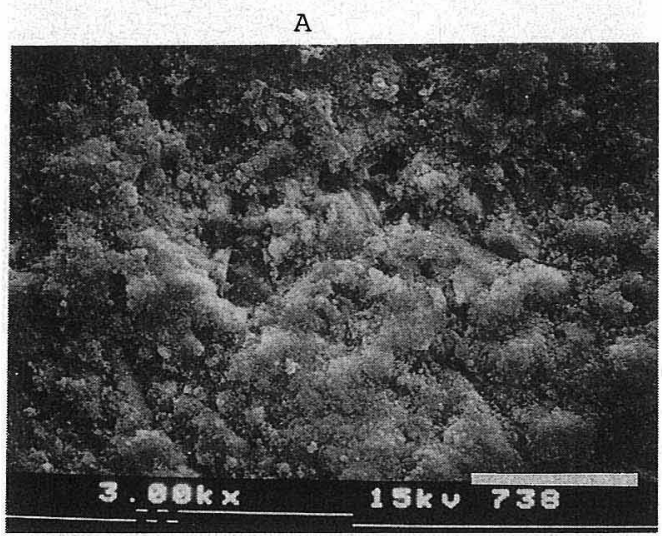

B

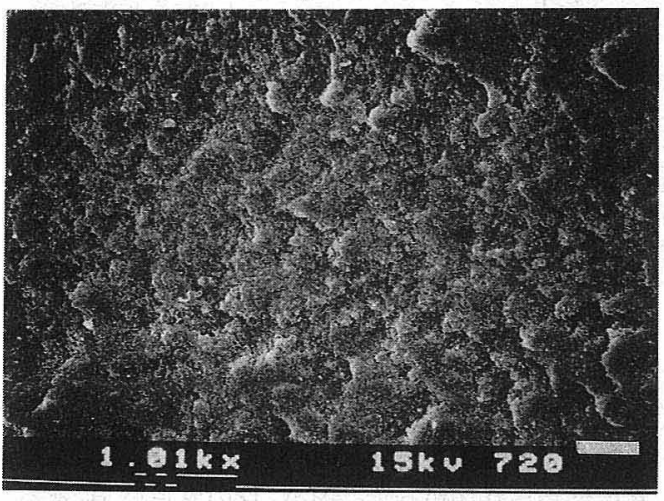

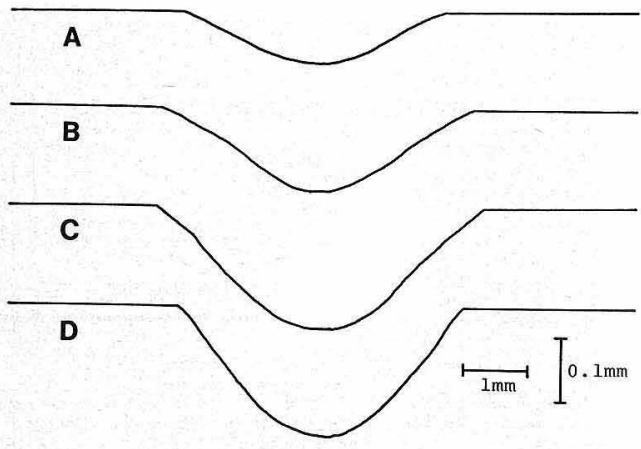

Fig. 9. Cross sections of wear circle on SiC disk slid by $\mathrm{Si}_{3} \mathrm{~N}_{4}$ balls for about $3 \mathrm{~km}$.

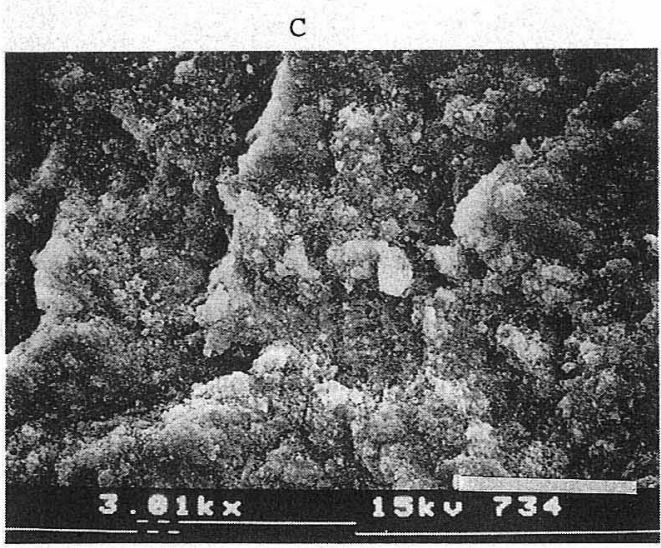

D

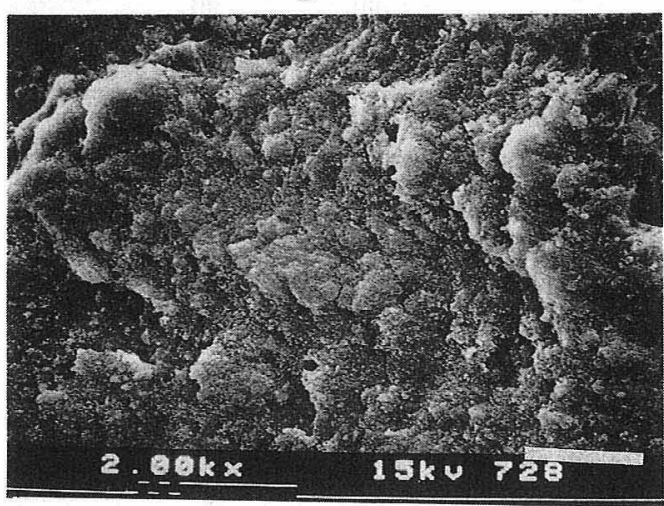

Fig. 10. Wear surfaces on $\mathrm{Si}_{3} \mathrm{~N}_{4}$ balls sliding on $\mathrm{SiC}$ disk at load $10 \mathrm{kgf}$ and velocity $20 \mathrm{~cm} / \mathrm{s}$. The lines are $10 \mu \mathrm{m}$.

る. マクロな $H_{\mathrm{v}}$ や $K_{\mathrm{IC}}$ では評価しきれない結晶粒界の 特性も摩耗には大きな影響を与えるようである。

\section{4. 総一括}

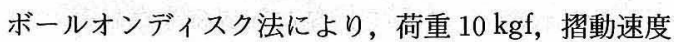
$20 \mathrm{~cm} / \mathrm{s}$ で, 4 種の $\mathrm{Si}_{3} \mathrm{~N}_{4}$ 球, $\mathrm{A}, \mathrm{B}, \mathrm{C}, \mathrm{D}$ と $\mathrm{SiC}$ ディ
スク間の摩耗試験を行った。その結果を要約すると以下 のようになる。

（1）粒径が大きく，気孔の多い A は硬さ，靶性が 低く，逆にち密で微細な針状組織を持つ D は高い硬さ， 靶性を示している.

（2）各 $\mathrm{Si}_{3} \mathrm{~N}_{4}$ 球上の摩耗痕形状から求められる摩耗 
量は重量減少に比例し，また摺動距離に比例して増加す る.

（３）各 $\mathrm{Si}_{3} \mathrm{~N}_{4}$ 球の摩耗は硬さあるいは靶性が高くな ると減少し, 逆に相手 $\mathrm{SiC}$ ディスクの摩耗は急速に増 大する.

（4）結晶粒界相を含むC の摩耗は非常に低く, 逆 に相手ディスクの摩耗は高くなっている.

文献

1) R. N. Katz, Int. J. High Tech. Ceram., 1, 69-79 (1985).
2) L. B. Sibley and M. Zlotnick, Mater. Sci. \& Eng., 71, 283-93 (1985).

3）竹林博明, 小松通泰, 機械設計, 29, 84-91 (1985).

4) 藤原孝誌, 竹林博明, 潤滑, 32, 367-70 (1987).

5）大工試ニュース, 32, No.2 (1988).

6) H. Czichos, S. Becker and J. Lexow, Wear, 114, 109-30 (1987).

7）岩佐美喜男，木下 実，窯協，95，899-905（1987）.

8) K. Niihara, R. Morena and D.P.H. Hasselman, J. Mater. Sci. Lett., 1, 13-16 (1982).

9）岩佐美喜男，溶射技術，6，1-10（1985）. 